\title{
Effect of premarital counseling on shyness and expectations from marriage among medical science students
}

\author{
Iman Seyyed Moharrami ${ }^{1}$, Malihe Pashib ${ }^{2 *}$, Anahita Zandi ${ }^{3}$, Seddigheh Abbaspour ${ }^{4}$ and \\ Abbas Ghodrati Torbati ${ }^{5}$ \\ ${ }^{1}$ MSc Consultant, Torbat Heydariyeh University of Medical Sciences, Torbat Heydariyeh, Iran \\ ${ }^{2}$ MSc Clinical Psychology, Torbat Heydariyeh University of Medical Sciences, Torbat Heydariyeh, Iran \\ ${ }^{3}$ MSc Nursing Faculty Member Torbat Heydariyeh University of Medical Sciences, Torbat Heydariyeh, Iran \\ ${ }^{4}$ MSc Faculty Member, Torbat Heydariyeh University of Medical Sciences, Torbat Heydariyeh, Iran \\ ${ }^{5}$ Faculty Member Medical University of Torbate Heydariyeh, Torbate Heydariye, Iran
}

\begin{abstract}
The period before from marriage is the one of the sensitive and critical periods in life and also is very influential period in preventing marital problems after marriage. The aim of this study is to investigate the effect of premarital Counseling on shyness and expect from marriage among students of Medical Sciences, Torbat Heydariyeh, Iran. This quasi-experimental study was conducted on 30 single students of Medical Sciences in Torbat Heydariyeh Iran. The assessment tools was shyness and expect from marriage scales that were complete $d$ in the pre-test and post-test by participants. The intervention group participated in 8 sessions of premarital Counseling and the control group received no intervention. Data were analyzed using descriptive and Analytic statistics. The mean age of participants in control and intervention groups was $19.33 \pm 0.61$ and $19.92 \pm 1.07$ years, respectively. There was no significantly different between background variables of two groups ( $p>0.05)$. In the control group there was no significant difference in shyness and expect from marriage, before and after the study, but there was a significant difference between two mentioned variables in the intervention group $(\mathrm{p}<0.05)$. According to the results, it is suggested that premarital Counseling used for students before Choice of spouse until to reduce the disturbing factors in spouse selection process. Premarital Counseling improves shyness, cynical and idealistic expectations from marriage.
\end{abstract}

KEY WORDS: PREMARITAL COUNSELING, SHYNESS, MARRIAGE, EXPECT FROM MARRIAGE

\section{ARTICLE INFORMATION:}

*Corresponding Author:

Received $27^{\text {th }}$ June, 2017

Accepted after revision $27^{\text {th }}$ Sep, 2017

BBRC Print ISSN: 0974-6455

Online ISSN: 2321-4007 CODEN: USA BBRCBA

;. Thomson Reuters ISI ESC and Crossref Indexed Journal

- NAAS Journal Score 2017: 4.31 Cosmos IF: 4.006

- A Society of Science and Nature Publication, 2017. All rights reserved.

Online Contents Available at: http//www.bbrc.in/

DOI: $10.21786 / \mathrm{bbrc} / 10.3 / 5$ 


\section{INTRODUCTION}

Formal legal marriage is a contract that is closed between men and women and Considers for each person special place and role (Houlgate, 2017). In recent years the use of pre-marital counseling program to strengthen marriage is common. Premarital counseling for couples preparation and prevent dissatisfaction and failure in marriage has a significant impact and people learn how to be a successful and stable marriage, so premarital counseling have aspects of preventive, educational and therapeutic (Parhizgar et al., 2017). The research shows that traditional counseling before marriage is not benefiting for married life and had not a positive impact on the stability of marriage (Moeti et al., 2017).

Premarital period is one of the sensitive and critical points in life and is a very effective period in the continuity of life and prevention of marital problems after marriage (Vural \&t Temel, 2009). In post marital period, one of the factors that cause a basic change in the process of marriage and its path is expect of people from marriage, roles and marital needs (Bagarozzi, 2014). According to the findings of researchers, having optimum belief, attitude and expect from marriage is the best and most important capital in marriage and guarantees more happiness of people in the common marital path. Expects and beliefs of people from marriage affect the perception of people from each other and probability of marriage or non-marriage and determination of marriage time (Parrott \& Parrott, 2005).

Expectations from marriage is a set of realistic, idealistic and cynical expects that shows the beliefs of people to triple fields of marriage namely intimacy, agreement and equality. expect from marriage shows the expects of people from the level of intimacy and closeness to the spouse, type of personality and attractiveness of future spouse, type of activities inside and outside of family, and the rate of responsibility and equality of couples in the affairs related to home and children (Nilforooshan, Abedi, Ahmadi, \& Navidian, 2011). Expectations from marriage in people in premarital period has a significant relationship with married life and life satisfaction like the level of intimacy, distance, division of labor, and the nature of the relationship between husband and wife with the main family (Holman, 2006). Theoretically, the primary experiences of the persona and relationships, whether as the observer of a relationship or participant in it, has a main role in the formation of expect from marriage. According to the Bowlby's attachment theory, the primary experiences of person in relationship with the beliefs and expects of people from the next relationships (Mikulincer \& Shaver, 2007).

The study of expectations from marriage in premarital period is very important so that the researchers in a study examined and graded the areas of couples problems and mentioned the unrealistic problems and expect from marriage and lack of intimacy and interest as the most important marital problem (Mazlomi, Dolatshahi, \&t Nazari, 2010). One of the other important issues that can affect the decisions of people in marriage is shyness. Shyness is associated with several distinct behavioral antecedents and biological correlates across development, including early behavioral inhibition and neuroendocrine dysregulation, (Poole et al., 2017).

Shyness has become the main concern of different societies during the recent years and has become an important issue, so that it has led the researchers toward understanding this problem (Koydemir \&t Demir, 2008). Shyness is considered as a kind of social anxiety that is defined with the features like anxiety in front of an audience, distress and worry and shyness from being seen by others (Botvin \& Kantor, 2000). Paying too much attention to the words and behaviors of oneself and fear of interaction with others, fear of not being confirmed by others and worry of being judged is the main features of shy people. These people make conditions stressful and while being exposed to new situations or new people with illogical and automatic thoughts and usually avoid asking questions or even answering the questions of others (Shahri et al., 2014).

The study results of Afrooz show that the increase of the people who have problem in relationships with others, those who have fear of social contacts and are shy, the young people who do not know what to say and how behave when they enter a group, sense of inability to talk to people and lack of cooperation with them, depression and social isolation and finally rejection by society (Afroz, 2002). Studies show personality and therefore also shyness is influenced by various sociodemographic variables, social roles and important events, which affect stability and lead to changes in personality (Van Zalk, Lamb, \&t Jason Rentfrow, 2017). Also Poole, Van Lieshout \& Schmidt believe emerging evidence suggests that conflicted shyness (combination of shyness and sociability) places individuals at risk for maladjustment in childhood, adolescence, and emerging adulthood (Poole, Van Lieshout, \&t Schmidt, 2017).

Since expectations from marriage is one of the most important factors to guarantee post marital satisfactions and on the other hand shy people are susceptible to make wrong decisions for marriage, without a doubt these two areas of evaluation have an important role in the guarantee of right decisions for marriage. For this purpose, today it is attempted to use the premarital programs for single people. Premarital counseling is a new approach that presents some education in order to prevent the post marital dissatisfaction (Salarvand, Bahri, Heidary, \&t Khadive, 2011). 
The experts of family area are suing about the efficiency of premarital counseling and teach people how to have a successful and durable married life (Fathzadeh et al., 2008). To final purpose of premarital counseling is to help the strength and stability of marriage, the reduction of divorce rate and promotion of marriage quality. Premarital counseling program with the study of effective factors in successful marriage and the role of these factors in the supply of adjustment and marital life satisfaction deal with some approaches to select the appropriate spouse and successful marriage and also prevent frustration in married life and study of its dimensions and factors through the mutual understanding of spouses, understanding the needs of both sides, mutual understanding, love, kindness and mutual commitment (MirMohammad Sadeghi, 2010). Although the effectiveness of premarital counseling to promote the level of life has been examined but its effect on expect from marriage and shyness of single students has been les studied. Thus, the present study aims to investigate the effect of premarital counseling on shyness and expect from marriage among students of Medical Sciences, Torbat Heydariyeh, Iran.

\section{MATERIAL AND METHODS}

The present study was a quasi-experimental intervention with pre-test, post-test and control group. The statistical population includes all single and new arrival students of Torbat Heydarieh university of medical sciences in $1394(\mathrm{n}=110)$. After taking the licenses from Torbat Heydarieh university of medical sciences and taking conscious consent of the participants, 30 single students were selected by random-stratified method and were placed in the intervention group and control group (groups of 15) by random allocation method. The inclusion criteria of participants to the study were gaining high score and very low score in the scale of expect from marriage and gaining a score more than 67 in shyness test. At the beginning of the study, the scale of expect from marriage and shyness scale was completed by the participants of intervention group and control group. Premarital counseling was performed in 8 sessions of 2 hour for the intervention group. During this time, the control group did not receive any education. The summary of activities in intervention sessions are as follows:

The first session; teaching concepts familiar, attractive, familiar theories, advantages and limitations of familiarity, ten mistakes in the process of dating and matchmaking.

Second session; Training love triangle theory, the elements of love, the effect of the issue on love, choose love and complete unfinished love children and facilitate
donors.Third session; Life skills training including assertiveness skills, effective communication skills, assertiveness, stress management, anger management, etc. Fourth Session; Training process of mate selection, right and wrong reasons to marry, false expectations of marriage, people who are not suitable for marriage, personality disorder and inappropriate for marriage, good relationships that are not marriage, married warning signs, criteria of successful marriage. Fifth Session; Defining engagement, the marriage, the difference candidate with familiarity, forced marriage, commitment concepts, borders and boundaries, and the time of engagement. Sixth Session; the Marriage period, definition of marriage period, difference between marriage and engagement, requirements and functions of marriage period. Seventh session; Issues related to family, wife, threads between family, family issues related to the main economic issue, dowry, dowry, etc., division of labor in the process of marriage and expectations associated with these conditions and preparing participants for sessions. Eighth Session; Informing students about early marriage and its challenges, build confidence, balance between the need for affiliation and need for independence, competitors, marriage, having children and sessions. After the end of training secessions, the participants of intervention and control groups completed the questionnaires again. The measurement tool was the standard questionnaire of Jones and Nelson expect from marriage and Stanford shyness.

Marriage expectation scale (MES) includes 40 items and 3 sub scales of cynical expect, realistic expects and idealistic expects. Its scoring range was graded according to Likert 5-point scale as totally disagree with 1 to totally agree with 5 . The minimum score in this scale is 40 and maximum score is 200. Lower scores show cynical expect from marriage and higher scores show idealistic expect from marriage. Average scores show realistic expects (Nilforooshan et al., 2011). Jones and Nelson reported the reliability of questionnaire for the total scale by Cronbach's Alpha as 0.79 to 0.80 and Dilon as 0.80 (Dillon, 2005; Jones \&t Nelson, 1997). The reliability of this questionnaire in the present study was obtained as 0.74 .

Stanford shyness scale includes 40 items that was made in Stanford University and measures the shyness of people. Stanford shyness scale is in all questions with Likert 4-point scale including never (code 1), sometimes (code 2), often (code 3), and always (code 4). The minimum score is 40 and maximum score is 160 . The score from 40 to 60 shows low shyness. 67 to 100 average shyness and more than 100 shows high shyness. In the study of Najaf Abadi et al., the validity of shyness was 0.74 and its reliability was obtained as 0.87 by Cronbach's Alpha method ( Najaf Abadi et al., 2013). In the 
present study, the reliability of the tool was confirmed as 0.77 for Cronbach's Alpha. The statistical data of the study were analyzed by using SPSS statistical software version 21.

\section{RESULTS AND DISCUSSION}

The man age of participants in the control group was $19.33 \pm 0.61$ and in intervention group was $19.92 \pm 1.07$. In the control group 7 subjects (47.7\%) and in intervention group 6 subjects (40\%) were women. The frequency of medical emergencies was 5 subjects (33.3\%), midwifery 7 subjects (46.7\%) and anesthesiology was 3 subjects $(6.7 \%)$ that this number is equal in both groups of control and experimental. In terms of economic status, the maximum frequency was related to average economic status with 10 subjects (66.7\%) in control group and 8 subjects $(53.3 \%)$ in the experimental group. The use of Chi-2 statistical tests for the variables of gender, economic status, education and independent T-test for age showed that there is not a significant difference between the mentioned variables in the two groups of control and experimental $(p>0.05)$. It means that the two groups were homogenous in terms of the mentioned variables.

To compare the amount of shyness between the two groups of control and intervention before and after intervention, the Mann-Whitney test was used. This test did not show any significant difference between the two groups before intervention in terms of shyness in students. $(p=0.96)$ But after the intervention, there was a significant difference between the two studied groups in terms of shyness $(p=0.01)$. To study the two groups before and after the intervention of the Wilcoxon test was used. The results show that in the control group after the intervention, there was no statistically significant difference in the degree of shyness $(p=0.31)$. But there was a statistically significant difference in intervention group $(p=0.01)$. So that at the beginning of the study, 4 subjects had severe shyness (26.7\%) and 9 subjects had average shyness (60\%) in the experimental group but after the intervention, the number of shyness reduced to 0 subjects (0\%) and average shyness reduced to 6 subjects (40\%) (Table 1$)$.

The second hypothesis of the present study claimed the significant difference between the intervention group and control group in terms of expect from marriage. The obtained score of any sub scale, the relevant questions were added together and since the score range for each sub scale is different, each range was considered as 0 to 100 for the better understanding of scores range. The results of kolmogrov-smirnov showed that expect from marriage and its sub scales (realistic expects, cynical expects, idealistic expects) are normal in the control and experimental group before and after the intervention ( $p>0.05)$. Accordingly, the parametric tests were used for analysis.

The results of independent t-test showed that the intervention and control group had no significant difference at the beginning of the study in terms of the score of expect from marriage $(p>0.05)$. It shows the assimilation of sample in the two groups according to the intended variables, but these were a significant difference after the performance of premarital counseling for intervention group $(\mathrm{p}<0.05)$ (Table 2$)$.

To study the two groups before and after the intervention, the Paired t-test was used. The results of paired T-test showed that the mean score of expect from marriage in students after holding premarital sessions in intervention group $(\mathrm{p}<0.05)$. This difference was not seen in the control group. ( $>0.05$ ) (Tables 3, 4 and 5).

According to the obtained results, premarital counseling has a significant effect on the shyness of students. Bashirpoor et al in a study compared the effect of group counseling with cognitive - behavioral approach and existential approach on the decrease of shyness in students. Both approaches had a significant effect on the shyness of male students but in their study, the interven-

\begin{tabular}{|c|c|c|c|c|c|}
\hline Variable & time & Variable classes & Control & Experimental & $P^{b}$ \\
\hline \multirow{7}{*}{ shyness } & \multirow{3}{*}{ Before intervention } & Weak & $1(6.7)$ & $2(13.3)$ & \multirow{3}{*}{$0.96, z=-0.05$} \\
\hline & & Average & $11(73.3)$ & $9(60)$ & \\
\hline & & Severe & $3(20)$ & $4(26.7)$ & \\
\hline & \multirow{3}{*}{ After intervention } & Weak & $2(13.3)$ & $9(60)$ & \multirow{3}{*}{$0.01, z=-2.7$} \\
\hline & & Average & $11(73.3)$ & $6(40)$ & \\
\hline & & Severe & $2(13.3)$ & $0(0)$ & \\
\hline & \multicolumn{2}{|l|}{$P$-value ${ }^{\mathrm{c}}$} & $0.31, z=-1$ & $0.01, z=2.49$ & \\
\hline
\end{tabular}




\begin{tabular}{|c|c|c|c|c|}
\hline variable & time & Control & experimental & $P^{b}$ \\
\hline \multirow{3}{*}{ Realistic expects } & Before intervention & $51.17 \pm 7.46$ & $49.31 \pm 6.21$ & $0.46, \mathrm{t}=-1.67$ \\
\hline & after intervention & $49.31 \pm 7.39$ & $68.23 \pm 14.10$ & $<0.001, \mathrm{t}=-2.72$ \\
\hline & $P$-value ${ }^{\mathrm{c}}$ & $0.08, t=1.47$ & $<0.001, \mathrm{t}=4.56$ & \\
\hline
\end{tabular}

Table 3. The comparison of the mean score of idealistic expect from marriage in participants before and after intervention in the two groups ${ }^{\mathrm{a}}$

\begin{tabular}{|c|c|c|c|c|}
\hline variable & time & Control & experimental & $P^{b}$ \\
\hline \multirow{3}{*}{ Idealistic expects } & Before intervention & $70.95 \pm 15.06$ & $75.83 \pm 14.33$ & $0.46, \mathrm{t}=-0.9$ \\
\hline & after intervention & $73.45 \pm 12.51$ & $59.16 \pm 18.38$ & $0.02, t=-2.40$ \\
\hline & $P$-value ${ }^{c}$ & $0.09, \mathrm{t}=-1.78$ & $0.006, t=3.25$ & \\
\hline
\end{tabular}

tion method of group counseling was cognitive-behavioral and existential while in the present study the intervention method was premarital counseling (Bshirpoor, Salimibejestani, \&t Farahbakhsh, 2013). Also, Rahmani and BaniAsadi in a study examined the effectiveness of teaching non-verbal relationship on the shyness of students and the obtained results showed that these educations have decreased the shyness of students in physiological and behavioral dimensions. However, the intervention method in the study of Rahmani et al. was different from the present study (Rahmani \&t BaniAsadi, 2013).
To explain the obtained results, the attitude of Gudarzi et al can be mentioned. They believe that the science of life skills education as a preventive method can have positive and useful effects on the increase of emotion control, coping with stress, high self-confidence, and increase of self-concept, increases of self-esteem, better problem solving and interpersonal conflicts that lead to the reduction of shyness (Goudarzi, MakvandHosseini, Rezai, \&t Blotbngan, 2013).

In the present study, one of the discussions that were taught in sessions with students was teaching life skills such as establishing effective relationships,

\begin{tabular}{|c|c|c|c|c|}
\hline variable & time & Control & experimental & $P^{b}$ \\
\hline \multirow{3}{*}{ Cynical expects } & Before intervention & $65 \pm 13.65$ & $73.6 \pm 9.02$ & $0.06, t=3.25$ \\
\hline & after intervention & $57.73 \pm 8.86$ & $45 \pm 8.01$ & $<0.001, \mathrm{t}=-6.21$ \\
\hline & $P$-value ${ }^{\mathrm{c}}$ & $=0.09, \mathrm{t}=-1.76$ & $<0.001, \mathrm{t}=4.29$ & \\
\hline \multicolumn{5}{|c|}{$\begin{array}{l}\text { aValues are expressed as mean (SD). } \\
\text { bIndependent t-test results } \\
\text { 'Paired t-test }\end{array}$} \\
\hline
\end{tabular}

\begin{tabular}{|c|c|c|c|c|}
\hline variable & time & Control & experimental & $P^{b}$ \\
\hline \multirow{3}{*}{ Expects from marriage } & Before intervention & $54.41 \pm 24.11$ & $65.91 \pm 11.22$ & $0.13, t=-1.56$ \\
\hline & after intervention & $61.41 \pm 11.54$ & $54.29 \pm 4.81$ & $\mathrm{p}<0.001, \mathrm{t}=-4.22$ \\
\hline & $P$-value ${ }^{\mathrm{c}}$ & $0.1, t=1.64$ & $0.03, \mathrm{t}=2.2$ & \\
\hline
\end{tabular}


self-assertion, stress management and assertiveness and this education can be effective in the reduction of shyness in students. People attend the society with more self-confidence when they are equipped with social skills, so they create successful relationships and this success increases their self-confidence and anxiety to attend in front of an audience (Dokanei Fard, 2007). Mahruz Yadak and Hatami also confirmed the effect of teaching life skills on shyness and believe that people can make better decisions and cope with emotions like fear, anger, shyness or sadness in an appropriate way when they are equipped with these teachings (Mehroz Yadak \& Hatami, 2010). Also, premarital counseling improved the cynical and idealistic expects in most students. According to the results of the present study, premarital counseling could reduce cynical and idealistic expects and increase realistic expects. Before the intervention, the average realistic expects of students was low but after premarital counseling, the average realistic expects increased and this result was useful. The average cynical expects of students was high before the intervention and significantly decreased after the intervention. Also, the average idealistic expects of the intervention group had a significant difference before and after the intervention and this difference was not observed in the control group that did that did not receive any intervention.

The results of this study are in line with the study of Omidvar et al. they examined the effect of premarital Counseling on expects from marriage of students and the results showed that the counseling have a significant effect on expects from marriage (Omidvar, FatehiZadeh, \&t Ahmadi, 2009). Also, Sharp and Ganeng in their study proved the effect of systematic education on unrealistic and romantic expects of university students and showed that the students significantly adjusted their unrealistic and romantic expects due to education (Sharp \&t Ganong, 2000). To explain the obtained result, the content of the sessions of the present study can be mentioned. In the present study, one of the issues that were studied in group sessions was the issues that were studied in group sessions was the study of the role of wife and husband, expect of participants in the study from their future spouse, expects and objectives of participants from marriage and creating family. Negative reasons for marriage including space away from inappropriate family environment, economic problems and positive reasons for marriage like the need to love and intimacy, being parent and the need to accompany were clarified. The subjects were explained that cynical or unrealistic expects lead to frustration and the frustration due to the non-satisfied expects causes anger, and dissatisfaction from marital life (Ghahari, 2012).

Counseling can be a reason for the changes of idealistic and cynical expects from marriage. Also, in ses- sions, the technique of exploration was used to clarify the meaning of expect from marriage in people and their beliefs. The double standard technique was used to change the wrong expects. So that, the participants were asked: what will you say if your close friend has a similar selection like you and rely on his/her spouse to meet all his/her expects?

Double standard technique makes people look at their problem in such a way as if it is the problem of someone else. Though this method, the participants found that expects from marriage is unrealistic. In general, premarital counseling led to the improvement of shyness and expect from marriage.

\section{CONCLUSION}

According to the study results, it is suggested that premarital counseling is used before the selection of spouse in order to reduce nuisance factors in the process of choosing spouse. Premarital counseling could reduce shyness, idealistic and cynical expects from marriage by providing information on the field of risky marriages, relationships before marriage, barriers of appropriate process of information, teaching how to identify cognitive distortions and methods of challenging the false beliefs and effective relationships.

\section{ACKNOWLEDGEMENTS}

The authors sincerely appreciate all those involved in this research, especially Deputy of Education and Research of Torbat Heydarieh University of Medical Sciences who helped us with financial support (Research Project Code 34.2).

\section{CONFLICTS OF INTEREST}

The authors declare that there are no conflicts of interests regarding the publication of this article.

\section{REFERENCES}

Afroz, G. A. (2002). Psychology of Shyness and its Treatment (Vol. Sixth Edition). Tehran: Islamic culture.

Bagarozzi, D. A. (2014). Enhancing intimacy in marriage: a clinician's guide: Routledge.

Botvin, G. J., \& Kantor, L. W. (2000). Preventing alcohol and tobacco use through life skills training. Alcohol research and health, 24(4), 250-257.

Bshirpoor, M., Salimibejestani, H., \&t Farahbakhsh, K. (2013). To compare the effectiveness of group-based approach to existential and cognitive-behavioral consultant on the degree of shyness male high school students. Journal of Applied Psychology and research, 14(2), 51-60. 
Dillon, H. N. (2005). Family Violence and Divorce: Effects on Marriage Expectations. (Master of Arts in Clinical Psychology), East Tennessee State University.

Dokanei Fard, F. (2007). Life skills education impact on increasing students' self-esteem and reduce shyness. Journal of new ideas in education, 2(3), 43-56.

Fathzadeh, M., Bigi, M. A., Bazrgar, M., Yavarian, M., Tabatabaee, H. R., \&t Akrami, S. M. (2008). Genetic counseling in southern Iran: consanguinity and reason for referral. Journal of genetic counseling, 17(5), 472.

Ghahari, S. H. (2012). Premarital counseling. Guide psychologists, counselors and psychiatrists (Vol. Third edition). Tehran: QatrehPublishers.

Goudarzi, N., MakvandHosseini, S. H., Rezai, A. M., \& Blotbngan, A. A. (2013). Effective of teaching life skills to method of storytelling on the degree of shyness in students. Journal of Clinical Psychology Studies, 5(7), 121-136.

Holman, T. B. (2006). Premarital prediction of marital quality or breakup: Research, theory, and practice: Springer Science \& Business Media.

Houlgate, L. D. (2017). Family Contracts: Marriage and Divorce Philosophy, Law and the Family (pp. 171-201): Springer.

Jones, G. D., \&t Nelson, E. S. (1997). Expectations of marriage among college students from intact and non-intact homes. Journal of Divorce \& Remarriage, 26(1-2), 171-189.

Koydemir, S., \&t Demir, A. (2008). Shyness and cognitions: An examination of Turkish university students. The Journal of psychology, 142(6), 633-644.

Mazlomi, S., Dolatshahi, B., \&t Nazari, A. M. (2010). The effects of marriage enrichment program on increasing intimacy in couples without problem. Dena Journal, 5(3,4).

Mehroz Yadak, T., \&t Hatami, H. (2010). The effect of training life skills on reducing shyness and anger management in students.Proceedings of the Third Congress of Psychology.2010; 744-746. Paper presented at the Proceedings of the Third Congress of Psychology.

Mikulincer, M., \&t Shaver, P. R. (2007). Attachment in adulthood: Structure, dynamics, and change: Guilford Press.

MirMohammad Sadeghi, H. (2010). Premarital education Isfahan: Behzisti, Department of Cultural Affairs and prevention.

Moeti, B., Koloi-Keaikitse, S., \&t Mokgolodi, H. L. (2017). Married Women's Lived Experiences on the Value of Traditional Premarital Counseling "Go Laya" on Marital Stability in Botswana. The Family Journal, 1066480717710951.

Nadi Najafabadi, F., Nazarichegeni, A., \&t Mehrabizadeh, M. (2013). The causal relationship between shyness and loneli- ness with humor and self-esteem in girls mediation styles city of Najafabad. New Thoughts on Education, 9(2), 131150.

Nilforooshan, P., Abedi, A., Ahmadi, A., \&t Navidian, A. (2011). Studying the factor structure, reliability, and validity of the Marriage Expectation Scale (MES). International Journal of Behavioral Sciences, 5(1), 11-19.

Omidvar, B., FatehiZadeh, M., \& Ahmadi, S. (2009). The effect of premarital on marital expectations of students in Shiraz. Journal of family research, 5(18), 231-246.

Parhizgar, 0., Esmaelzadeh-Saeieh, S., Kamrani, M. A., Rahimzadeh, M., \&t Tehranizadeh, M. (2017). Effect of Premarital Counseling on Marital Satisfaction. Shiraz E-Medical Journal, 18(5).

Parrott, L., \&t Parrott, L. L. (2005). I Love You More: How Everyday Problems Can Strenghten Your Marriage: Zondervan.

Poole, K. L., Jetha, M. K., \&t Schmidt, L. A. (2017). Linking child temperament, physiology, and adult personality: Relations among retrospective behavioral inhibition, salivary cortisol, and shyness. Personality and Individual Differences, 113, 68-73.

Poole, K. L., Van Lieshout, R. J., \&t Schmidt, L. A. (2017). Shyness and Sociability Beyond Emerging Adulthood: Implications for Understanding the Developmental Sequelae of Shyness Subtypes. Journal of Social and Clinical Psychology, 36(4), 316-334.

Rahmani, R., \&t BaniAsadi, H. (2013). Effectiveness of Nonverbal Interaction Skills Training in the Decrease of Shyness. .Journal of Thought and Behavior, 7(26), 47-56.

Salarvand, S., Bahri, N., Heidary, S., \&t Khadive, M. (2011). Assessing Quality of the Pre-marriage Family Planning Consulting Classes: Viewpoints of Participant Couples. Journal of Isfahan Medical School, 29(128).

Shahri, M., Moeinikia, M., Zahed, A., \&t Narimani, M. (2014). Investigation the Impact of Paint Therapy on Communication Skills of Shyness Girl Students. Procedia-Social and Behavioral Sciences, 128, 327-331.

Sharp, E. A., \&t Ganong, L. H. (2000). Raising awareness about marital expectations: Are unrealistic beliefs changed by integrative teaching? Family Relations, 49(1), 71-76.

Van Zalk, N., Lamb, M. E., \& Jason Rentfrow, P. (2017). Does Shyness Vary According to Attained Social Roles? Trends Across Age Groups in a Large British Sample. Journal of Personality.

Vural, B. K., \&t Temel, A. B. (2009). Effectiveness of premarital sexual counselling program on sexual satisfaction of recently married couples. Sexual health, 6(3), 222-232. 